\title{
Surfaceome of pathogenic yeasts, Candida parapsilosis and Candida tropicalis, revealed with the use of cell surface shaving method and shotgun proteomic approach*
}

\author{
Justyna Karkowska-Kuleta\#, Dorota Zajac\#, Oliwia Bochenska and Andrzej Kozik ${ }^{\bowtie}$ \\ Department of Analytical Biochemistry, Faculty of Biochemistry, Biophysics and Biotechnology, Jagiellonian University in Kraków, Kraków, Poland
}

In the course of infections caused by pathogenic yeasts from the genus Candida, the fungal cell surface is the first line of contact with the human host. As the surfaceexposed proteins are the key players in these interactions, their identification can significantly contribute to discovering the mechanisms of pathogenesis of two emerging pathogens from this genus, C. parapsilosis and C. tropicalis. Therefore, the aim of the present study was to identify the cell wall-attached proteins of these two species with the use of cell surface shaving and a shotgun proteomic approach. Different morphological forms of C. parapsilosis and C. tropicalis cells obtained after growth under various conditions were subjected to this treatment. This allowed to indicate the most abundant cell surface proteins on the basis of the normalized spectral abundance factors. In case of yeast-like forms these were, among others, proteins similar to a chitinase, glyceraldehyde-3-phosphate dehydrogenase and an inducible acid phosphatase for C. parapsilosis, and a constitutive acid phosphatase, pyruvate decarboxylase and glyceraldehyde-3-phosphate dehydrogenase for C. tropicalis. In case of pseudohyphal forms, proteins similar to a cell surface mannoprotein Mp65, chitinase and glycosylphosphatidylinositol-anchored transglycosylase Crh11 were identified at the cell surface of $C$. parapsilosis. The Rbt1 cell wall protein, a hyphally regulated cell wall protein and proteins from agglutinin-like sequence protein family were found as the most abundant on C. tropicalis pseudohyphae. Apart from the abovementioned proteins, several additional covalently bound and atypical cell wall proteins were also identified. These results extend the current knowledge regarding the molecular basis of virulence of these two non-albicans Candida species.

Key words: cell surface shaving, proteomics, fungal pathogens, cell wall, Candida

Received: 30 July, 2015; revised: 18 September, 2015; accepted: 04 October, 2015; available on-line: 04 December, 2015

\section{INTRODUCTION}

The most external part of microbial cells, such as the fungal cell wall or bacterial envelope, confers their shape, rigidity and mechanical strength, being also responsible for proper growth, morphogenesis and reproduction. Moreover, the cell surface also acts as a protective barrier, providing a dynamic response to stress and changes in environmental conditions. Because cell wall/envelope for a variety of prokaryotic and eukaryotic pathogens is also a key structure that participates in interactions with the human host during infection, thus playing an important role in pathogenesis, a progressively growing number of studies has been devoted to different types of molecules localized at the pathogens' cell surface (Hecker et al., 2010; Silhavy et al., 2010; Free, 2013; Demuyser et al., 2014).

At present, after the release of genome sequences for a number of pathogenic microorganisms and due to the expanding development of the PCR-based techniques, the detection of changes in the gene expression correlated with infection process is often used in the studies of bacterial or fungal pathogenesis (Sturtevant, 2000). However, one still should bear in mind a fact that mRNA is only the short-time messenger and that translated proteins might undergo different regulation and posttranslational modifications, resulting in changes of their function, structure and localization. In fact, proteins are the key players in the life of the cell under physiological and pathological conditions; thus, their actual exposure at the cell surface should be studied, not only the gene expression, especially in the case of atypical surface-associated proteins devoid of typical signal for extracellular localization, for these reasons sometimes called "moonlighting proteins" (Karkowska-Kuleta \& Kozik, 2014). More suitable combined approaches, employing a wide range of proteomic techniques and genomic data, open new perspectives to understand the molecular mechanisms of host-pathogen interplay (Huang et al., 2002).

The complex characteristics of surfaceome - a set of surface-associated proteins being the most variable and complicated molecules that build the cells' envelopes - expand very rapidly, as a lot of data is now available about the proteins identified at the surface of Grampositive and Gram-negative bacteria, non-pathogenic and pathogenic fungi and even a few multicellular pathogens (Desvaux et al., 2006; Solis \& Cordwell, 2011; OlayaAbril et al., 2014). The identification of this type of proteins with a classical proteomic approach involving fractionation and two-dimensional electrophoretic separation is not problem-free, because of their high glycosylation state, low abundance, insolubility and anchoring in the cell membrane or within the polysaccharide scaffold, as well as due to the possible contaminations of samples

e-mail: andrzej.kozik@uj.edu.pl

\#These authors contributed equally to this work

*The results were presented at the 6th International Weigl Conference on Microbiology, Gdańsk, Poland (8-10 July, 2015).

Abbreviations: Als, agglutinin-like sequence; ASL, alkali sensitive linkages; CGD, Candida Genome Database; DTT, dithiothreitol; GPI, glycosylphosphatidylinositol; MS/MS, tandem mass spectrometry; NSAF, normalized spectral abundance factor; YAPD, yeast extractanimal peptone-dextrose; YPD, yeast extract-peptone-dextrose 
with proteins from other cell compartments (Pitarch et al., 2002). Thus, there has been an insistent necessity to develop new identification methods. A novel approach used for discovering the secrets of pathogens' cell surface is the shaving of the live cells with trypsin for a short period of time, with an assurance that the cells are still not damaged and the cell membrane remains intact, to avoid the cytoplasmic contamination (Olaya-Abril et al., 2014).

This new method designated as surfaceomics, combined with a shotgun proteomic approach, was successfully used for studying the cell surface proteinaceous components of different bacterial species, including Streptococcus pyogenes (Severin et al., 2007), Staphylococcus aureus (Solis et al., 2010) and Escherichia coli (Walters \& Mobley, 2009). Also for the non-pathogenic yeast Saccharomyces cerevisae (Insenser et al., 2010), opportunistic pathogen Candida albicans (Hernáez et al., 2010; Vialás et al., 2012; Gil-Bona et al., 2015b) and pathogenic fungus Cryptococcus neoformans (Eigenheer et al., 2007), a number of surfaceexposed proteins was identified with this approach.

Nowadays, in addition to the two most common fungal pathogens from the genus Candida - C. albicans and C. glabrata - a problem of increased incidence of severe infections caused by two other species with different virulence attributes - C. parapsilosis and C. tropicalis - has alarmingly emerged (Arendrup, 2013). The latter two species together account for over one fourth of all systemic candidiases in immunocompromised patients (Azie et al., 2012; Wang et al., 2014), which implies an urgent need to better describe the molecular mechanisms of their virulence. The structure and composition of the C. albicans and C. glabrata cell wall — being the first structure that contacts the host during invasion have been already fairly well characterized (de Groot et al., 2008; Castillo et al., 2008; Klis et al., 2009), contrary to the two other non-albicans Candida species with great clinical importance.

Apart from polysaccharides, such as chitin, $\beta$-glucans and mannans, that serve as the mechanical scaffold of candidal cell wall, several groups of covalently bound or more loosely associated proteins are found at the Candida spp. cell surface. They are not only involved in a wide variety of physiological processes, but also act as important virulence factors that mediate the adhesion, biofilm formation, iron acquisition and proteolysis (Chaffin, 2008; Modrzewska \& Kurnatowski, 2015). The aim of this work was to identify the cell surface-exposed proteins at the cell walls of different morphological forms of C. parapsilosis and C. tropicalis - unicellular, yeast-like cells or filamentous pseudohyphae — observed under different cultivation conditions that mimic cellular stress, nutrient starvation or host invasion. Such a comprehensive characterization could be used in the future to design new, broad-spectrum anti-candidal vaccines, as well as differentiating diagnostic methods, or to design new and effective antifungal therapy against candidiases caused by non-albicans Candida species.

\section{MATERIALS AND METHODS}

Yeast strains and culturing. The $C$. parapsilosis strain CDC 317 (ATCC MYA-466) and C. tropicalis strain T1 (ATCC MYA-344) were purchased from American Type Culture Collection (Manassas, VA, USA). Cells were grown as yeast-like forms in YPD medium, pH $6.0(1 \%$ yeast extract, $2 \%$ soybean peptone and $2 \%$ glucose) (Sig$\mathrm{ma}$, St. Louis, MO, USA) at $30^{\circ} \mathrm{C}$ for $16 \mathrm{~h}$. To induce formation of pseudohyphal forms, both strains were cultivated in a defined medium RPMI 1640, pH 7.4 (PAA Laboratories $\mathrm{GmbH}$, Pasching, Austria) at $37^{\circ} \mathrm{C}$ for 48 $\mathrm{h}$ or in YPD buffered medium with lowered content of animal-derived peptone (YAPD), pH 7.0 (0.1\% yeast extract, $0.2 \%$ peptone from animal proteins, $2 \%$ glucose and $10 \mathrm{mM} \mathrm{NaH} \mathrm{PO}_{4}$ ) (Sigma) at $37^{\circ} \mathrm{C}$ for $48 \mathrm{~h}$. In certain cases, a sterile filtered human plasma was added to YPD or RPMI 1640 medium to a final concentration of $10 \%(\mathrm{v} / \mathrm{v})$.

Cell surface shaving with trypsin. C. parapsilosis or C. tropicalis cells $\left(5 \times 10^{8}\right)$, grown in the appropriate culturing medium were separated by centrifugation ( 5 minutes, $3000 \mathrm{rpm}$ ), observed under microscope to confirm their existence as the yeast-like form after YPD-culturing or the filamentous form after YAPD- or RPMI 1640-culturing, and then washed three times with $1 \mathrm{ml}$ of $25 \mathrm{mM}$ ammonium bicarbonate buffer $\left(\mathrm{NH}_{4} \mathrm{HCO}_{3}\right)$. The cell pellet was then resuspended in $100 \mu \mathrm{l}$ of the same buffer with $5 \mathrm{mM}$ dithiothreitol (DTT). Sequencing-grade trypsin $(10 \mu \mathrm{g})$ (Promega, Madison, WI, USA) was added to the cell suspension for incubation at $37^{\circ} \mathrm{C}$ for 5 minutes. After that, cells were centrifuged (5 minutes, $6000 \mathrm{rpm}$ ) and the supernatant was filtered through a filter with $0.22 \mu \mathrm{m}$ pores and subjected to further incubation with trypsin for 5 hours at the same temperature. The cell membrane integrity of the remaining cells was tested by staining with SYTOX ${ }^{\circledR}$ Green (Invitrogen Life Technologies, Carlsbad, CA, USA) and Trypan Blue (Sigma). After incubation, trifluoroacetic acid (TFA) (Sig$\mathrm{ma}$ ) was added to the supernatant to a final concentration of $0.1 \%$, to stop the enzymatic reaction. The sample was then incubated on ice for 15 minutes and after that centrifuged (15 minutes, $12000 \mathrm{rpm})$, dried in a SpeedVac (Martin Christ, Osterode am Harz, Germany) and frozen until further use.

Protein identification with LC-MS/MS and further statistical analyses. The peptides were separated and analyzed with a HCTUltra ETDII ion-trap mass spectrometer equipped with an electrospray ionization ion source (Bruker, Bremen, Germany) and coupled to an ultra-high-performance liquid chromatography Dionex Ultimate 3000 system. All peptide samples were first dissolved in $100 \mu \mathrm{l}$ of loading buffer $(10 \%$ acetonitrile with $0.1 \%$ formic acid), centrifuged (10 minutes, $10000 \mathrm{rpm}$ ) and, after transferring to fresh vials, separated on a $100 \mathrm{~mm} \times 2.1 \mathrm{~mm}$ Accucore C18 column (particle size of $2.6 \mu \mathrm{m}$ ) (Thermo Fisher Scientific, Waltham, MA, USA), with a gradient of $10-60 \%$ of $0.1 \%$ formic acid in $80 \%$ acetonitrile for $60 \mathrm{~min}$ utes with a flow rate of $0.2 \mathrm{ml} / \mathrm{min}$. The mass spectrometer was operated in a standard MS/MS mode with simultaneous fragmentation of the most intensive precursor ions by collision-induced dissociation and electron-transfer dissociation. Mascot Generic format (.mgf) files were generated by pre-processing the raw data with Data Analysis 4.0 software (Bruker). The lists of obtained peaks were searched against the nonredundant protein database of the NCBI with taxonomy restriction to Fungi (26 490256 sequences for all entries, 1935595 sequences for fungal proteins) or SwissProt protein database with taxonomy restriction to Homo sapiens (548 872 sequences for all entries, 20282 sequences for human proteins) using an in-house Mascot server (v.2.3.0; Matrix Science, London, UK). The following search parameters were applied: enzyme specificity - trypsin; permitted number of missed cleavages - 2; fixed modification - carbamidomethylation (C); variable modifications - oxidation $(\mathrm{M})$; protein mass 
- unrestricted; peptide mass tolerance of $\pm 0.3 \mathrm{Da}$ and fragment mass tolerance of $\pm 0.5 \mathrm{Da}$.

After peptide identification a final dataset was created on the basis of the classical mathematical normalization, named the normalized spectral abundance factor (NSAF) that allows to estimate the relative protein abundances. The NSAF was calculated using the following formula

$$
\mathrm{NSAF}=\frac{\frac{\mathrm{SpC}}{\mathrm{L}}}{\sum_{\mathrm{i}=1}^{\mathrm{N}}\left(\frac{\mathrm{SpC}}{\mathrm{L}}\right)}
$$

where the total number of spectral counts $(\mathrm{SpC})$, divided by the protein's length (L) was divided by the sum of the total number of MS/MS spectra for all proteins identified in the experiment in one sample.

\section{RESULTS}

\section{Identification of C. parapsilosis and C. tropicalis cell surface-exposed proteins}

A rapid and simple approach - cell surface shaving with trypsin, combined with shotgun proteomics - was applied in the present study to identify the cell surface-exposed proteins from different morphological forms of two opportunistic pathogens, C. parapsilosis and C. tropicalis (Fig. 1). Our observations indicated that in rich, complete YPD medium, the cells of both species existed as unicellular, yeast-like forms, while in the two other media, as filamentous pseudohyphal forms. The YAPD medium, characterized by the reduced amount of

Candida tropicalis or Candida parapsilosis culture growth under different conditions inducing morphological transition

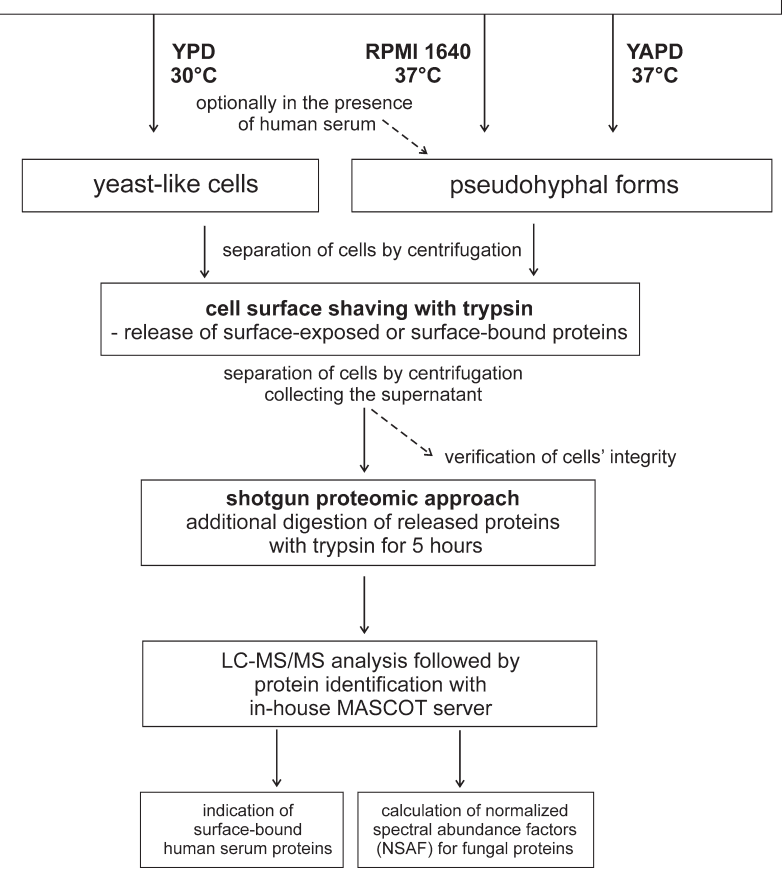

Figure 1. The workflow strategy for the identification of fungal surface-exposed proteins or human proteins bound to fungal surface, using the cell surface shaving method and shotgun proteomic approach. nitrogen due to the animal peptone, primarily stimulates the production of proteinases (Rapala-Kozik et al., 2010), although at the temperature of $37^{\circ} \mathrm{C}$ and $\mathrm{pH} 7.0$ it also causes the generation of filamentous forms. However, in YAPD medium the cells were elongated to a relatively lesser extent than in the case of the other growth conditions used - a defined, cell cultivating medium RPMI 1640 - that is typically used for inducing pseudohyphal growth of Candida spp. at $37^{\circ} \mathrm{C}$ (Hoyer et al., 1995).

A slightly modified method for digestion of fungal surface-exposed proteins was used in this study in comparison to that described previously for $C$. albicans by Hernáez et al. (2010), Vialás et al. (2012) and Gil-Bona et al. (2015b). Namely, proteins released from the cell wall during the five-minute incubation with trypsin, after separation of the supernatant from fungal cells, were further incubated with trypsin at $37^{\circ} \mathrm{C}$ for additional five hours to improve tryptic-digestion efficiency and to increase the number of peptides produced. The crucial condition during the whole treatment was to maintain the intact cell membrane without cell lysis, in order to avoid cytoplasmic contamination; therefore the cell integrity was confirmed after each experiment with specific staining.

This applied approach allowed us to identify 16, 9 and 12 proteins for C. parapsilosis and 13,13 and 10 proteins for $C$. tropicalis, assigned to cells grown in YPD, YAPD and RPMI 1640 medium, respectively. The calculation of NSAF for each protein identified in a particular sample enabled us to select and rank the relatively most abundant fungal proteins for each growth medium (Zybailov et al., 2007). All abbreviated names and protein descriptions included in this study were taken from NCBI protein database and Candida Genome Database (CGD) (Inglis et al., 2012). Although the genome sequences for these two particular Candida spp. strains were recently released (Butler et al., 2009), their proteome is still poorly characterized and described, therefore the identified C. parapsilosis and C. tropicalis hypothetical proteins were compared and assigned to orthologous genes and/or proteins from C. albicans.

As shown in Tables 1 and 2, some of the identified proteins were common for all tested conditions, such as C. parapsilosis orthologs of Phr2, Mp65, Pir1 and Ecm33, and $C$. tropicalis ortholog of Tdh3. Some proteins were unique, as for example proteins similar to $C$. albicans Rbe1, Plb5, Eng1 and Tos1 identified in C. parapsilosis and proteins similar to $C$. albicans Rbt1, Hyr3 and Als1 identified in C. tropicalis, which were present at the cell surface only after growth in the RPMI 1640 medium.

Within the particular sets of proteins derived from the cells cultured under defined conditions, the percentage content of proteins equipped with glycosylphosphatidylinositol (GPI) anchor that links them covalently to the cell wall was determined on the basis of structural annotations located in CGD. For both investigated species, the highest content of GPI-linked proteins was detected for the cell walls of pseudohyphae grown in RPMI 1640 medium. It was $50 \%$ and $30 \%$, respectively - which corresponds to 6 and 3 proteins - for C. parapsilosis and C. tropicalis. What is more, for the latter species, no additional GPI-anchored protein was identified for other tested conditions, whereas for C. parapsilosis 4 $(25 \%)$ and $2(22 \%)$ proteins found at the surface of cells grown in YPD or YAPD broth, respectively, were assigned as equipped with GPI remnant.

In order to determine the functional characteristics of identified proteins, for each of them the specific function was assigned on the basis of manually curated Gene Ontology (GO) annotations from CGD. The results of these 


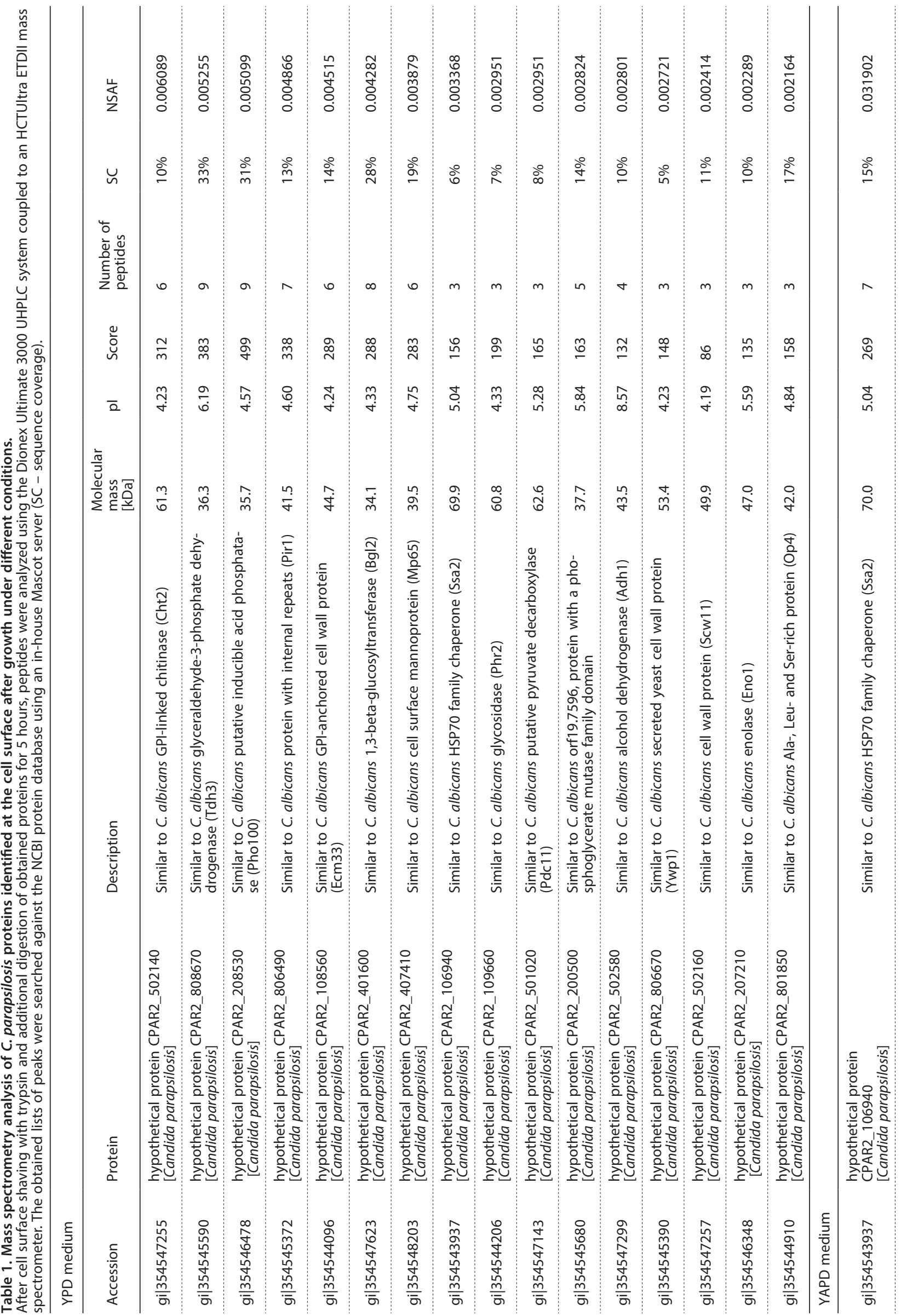




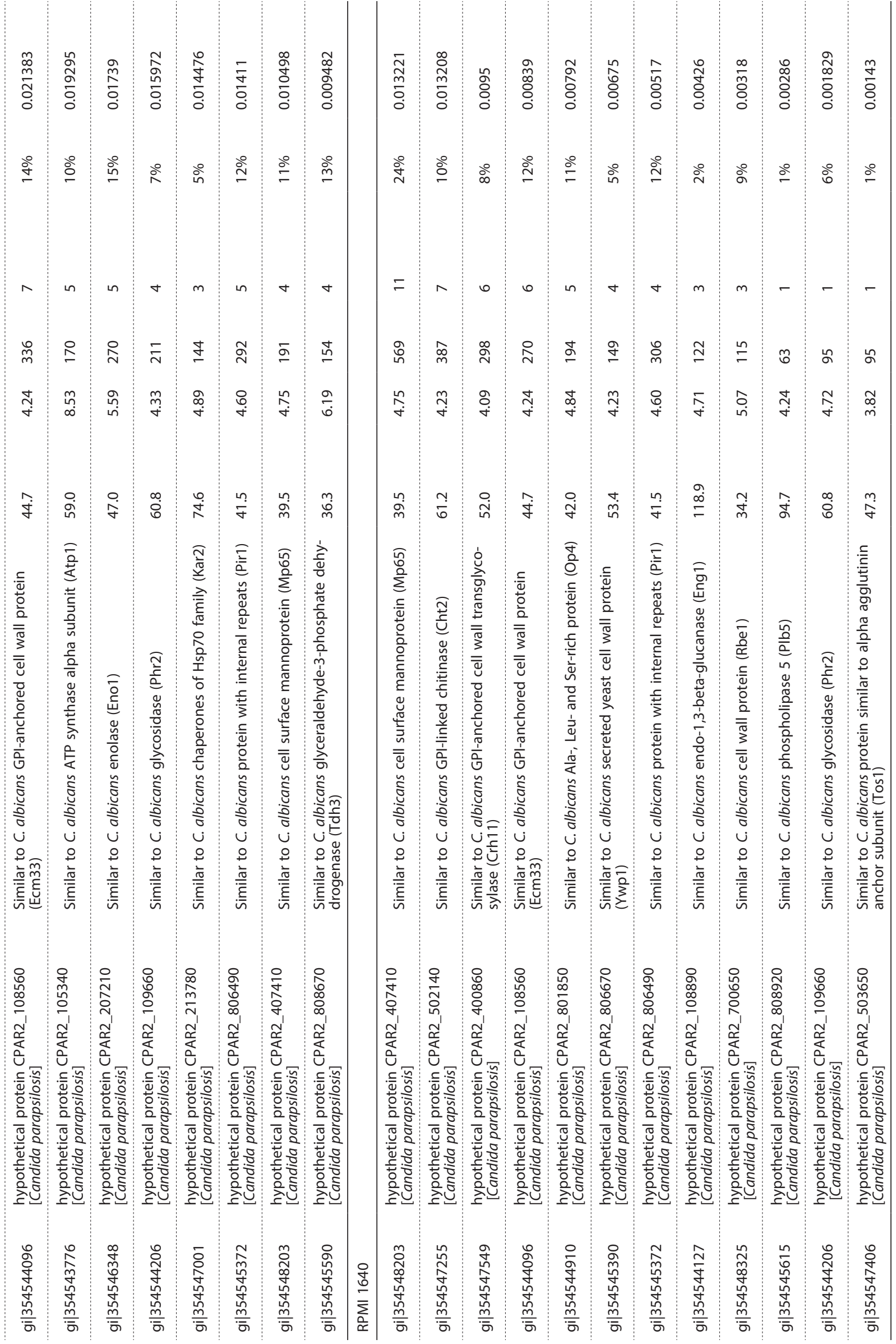




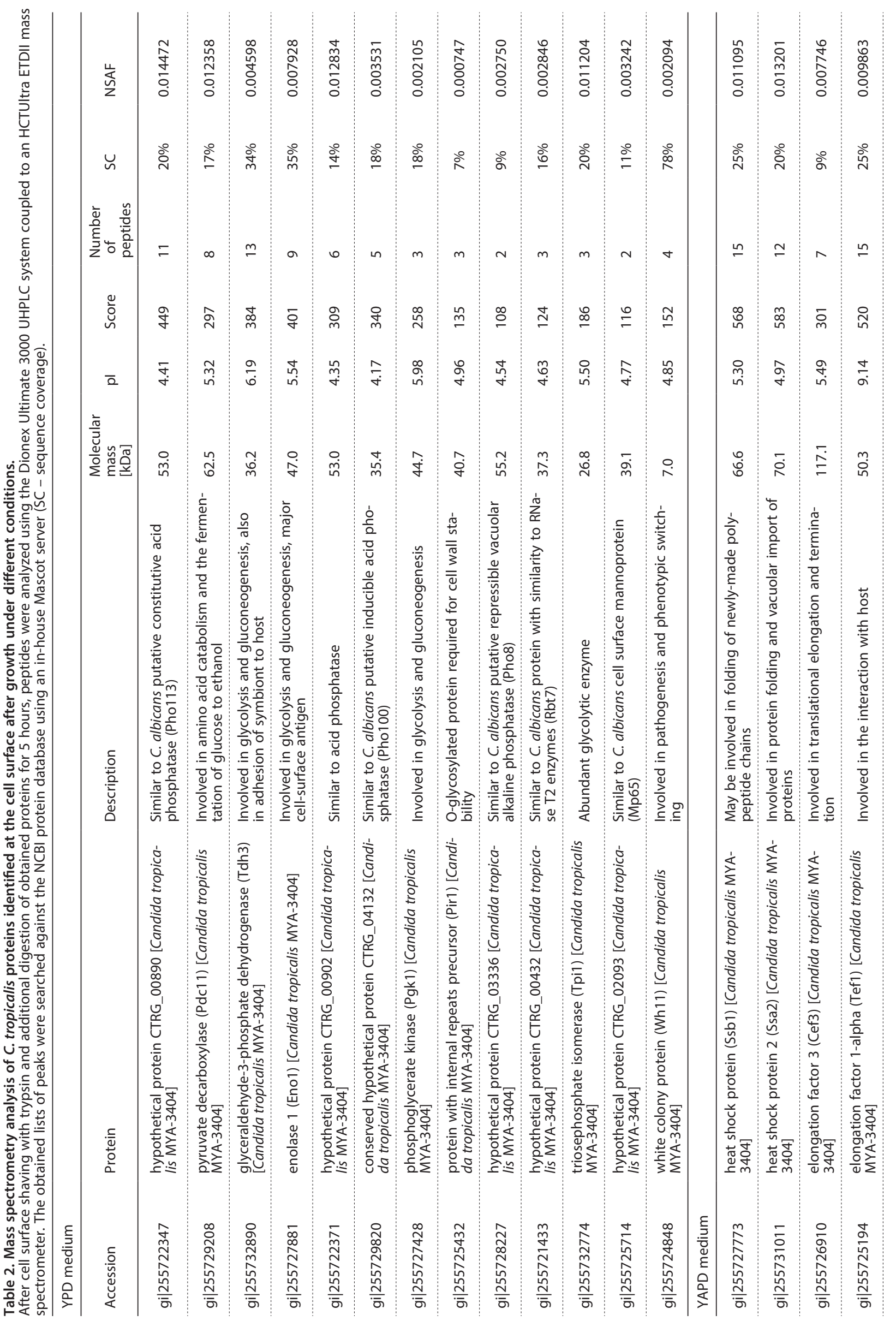




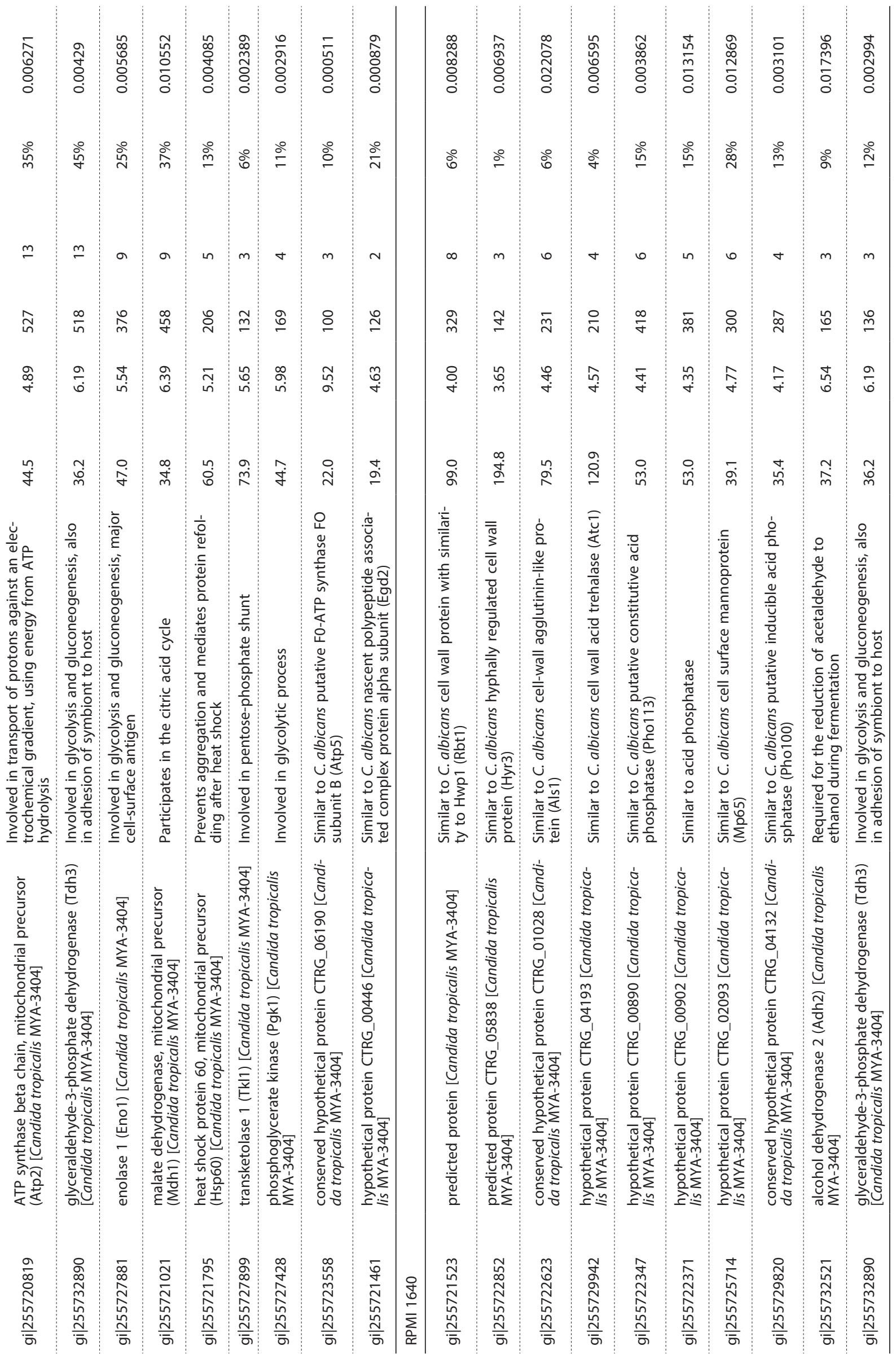




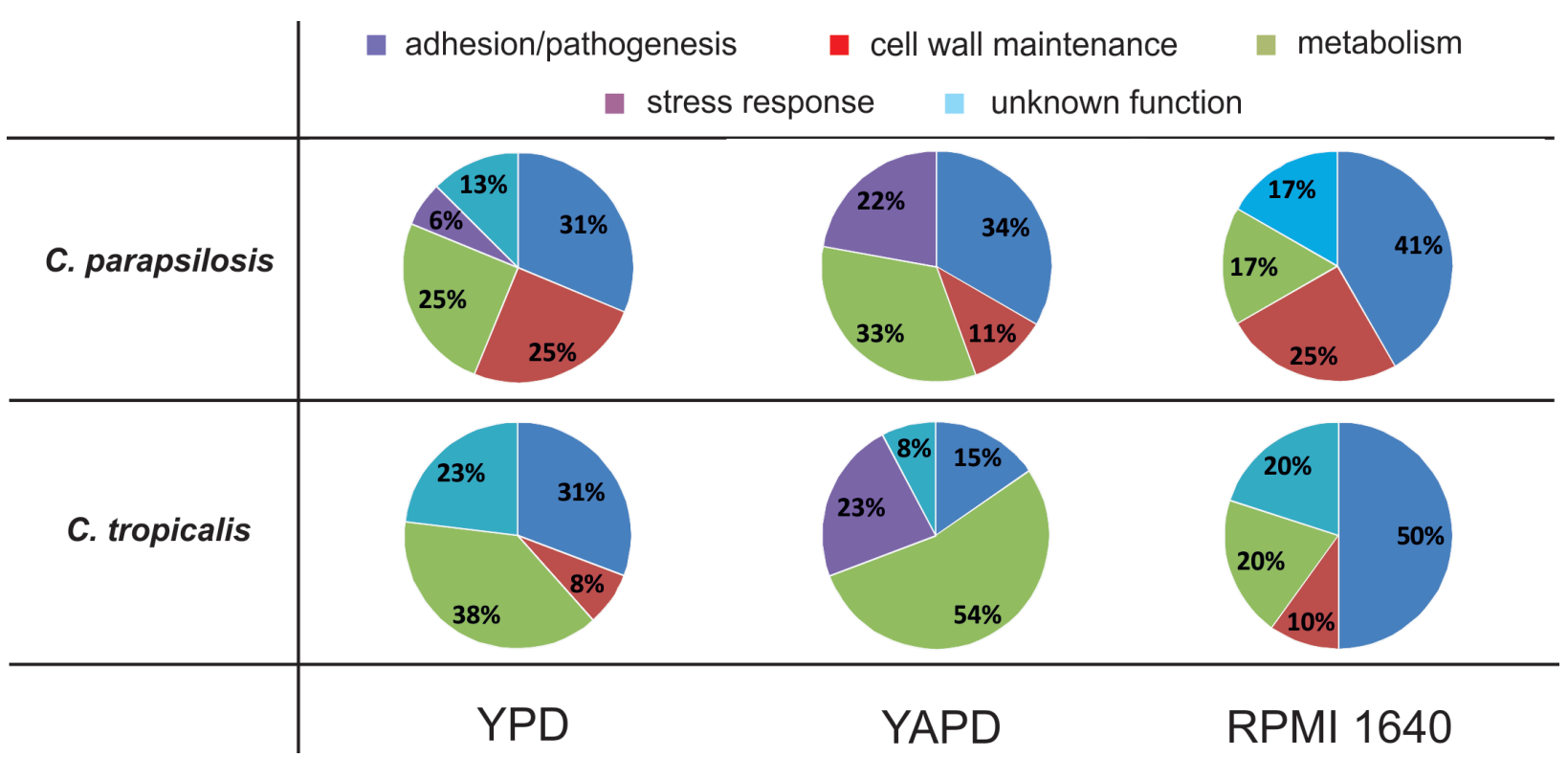

Figure 2. Functional classification of $C$. parapsilosis or $C$. tropicalis surface-exposed proteins identified with the cell surface shaving method and mass spectrometry.

Protein functions have been assigned on the basis of descriptions from NCBI protein database and orthologs' description in the Candida Genome Database.

analyses are summarized in Fig. 2, demonstrating some dependence between the functional profile of fungal surfaceome and the type of culture conditions and medium used. In case of C. parapsilosis cells, grown in RPMI 1640 medium, the most abundant group of proteins was that containing the adhesins and other virulence factors (41\%). For C. parapsilosis cells cultured in YPD or YAPD, the pathogenesis-related proteins were also the most frequent $31 \%$ and $34 \%$, respectively). However, for unicellular, yeast-like forms two groups of proteins - those involved in the cell wall maintenance or in the basic metabolism - were also strongly represented (both at 25\%). What drew our particular attention in case of $C$. parapsilosis cells cultured in YAPD - a nitrogen-deficient medium with lysate of animal proteins - was that the largest number of proteins involved in the stress response $(22 \%)$ was present at the fungal cell surface in comparison to other conditions applied. Similarly, for C. tropicalis cells grown in YAPD medium, 23\% of proteins were assigned as molecules involved in cell response to stress conditions and, moreover, it was the only sample wherein proteins from this group were found. Apart from that, about half of all identified proteins (54\%) were enzymes from basic metabolic pathways.

A comparable number of $C$. tropicalis proteins was identified as responsible for both physiological metabolism and pathogenesis (38\% and $31 \%$, respectively) in case of yeast-like forms grown in YPD broth. Importantly, $50 \%$ of proteins present at the cell surface of C. tropicalis pseudohyphae generated in RPMI 1640, were assigned as playing a role in the pathogenesis and adherence. It should be noted, however, that almost in each tested sample from both species there were some proteins with unknown/unassigned function and for this reason the described proportions could possibly slightly change after further characterization of these proteins.

\section{Human proteins bound at the cell surface of C. parapsilosis and C. tropicalis}

An approach similar to that described above, based on the shaving of the cell surface with trypsin followed by additional, prolonged digestion, was also applied to
C. parapsilosis and C. tropicalis cells grown in YPD or RPMI 1640 medium in the presence of human plasma at $37^{\circ} \mathrm{C}$ for 48 hours. The final identification of peptides obtained was classified as derived from human plasma proteins that were apparently adsorbed to the fungal cell surface and, as previously, from fungal proteins exposed at the cell surface of pseudohyphae (Table 3). A significantly lesser amount of candidal proteins found in these peptide samples as compared to the above-described determinations - six for C. parapsilosis and three for C. tropicalis - was probably a result of quite a large number of bound human proteins, apparently covering the surface of fungal cell and reducing its availability for trypsin. However, in spite of such difficulties, we were capable to indicate three proteins from each investigated Candida species, whose exposure at the cell surface was at least three-fold higher in the medium with human plasma than at the same conditions but without plasma. The differences have been calculated on the basis of NSAF obtained for the tested peptide samples. In case of C. parapsilosis, a protein from CFEM family and proteins similar to Ecm33 and Pir1 - two typical cell wall proteins - were more abundant at the cell surface after fungal contact with human plasma. In the case of C. tropicalis, apart from atypical protein Tdh3, two cellsurface proteins - a protein similar to Rbt1 and an adhesin from agglutinin-like sequence protein family were indicated as exposed at the cell surface in greater quantities, if pseudohyphae were formed in plasma-containing medium.

In addition, interesting results were obtained after searching the SwissProt protein database with restriction to human proteins in order to find molecules attached to the surface of fungal cells after growth under these "bloodstream infection-mimicking" conditions. 20 different proteins for C. parapsilosis and 19 for C. tropicalis were identified as adsorbed to the surface of fungal cells. The referred sets of identified human proteins were rather comparable in case of both investigated species, indicating a significantly shared preference for apolipoproteins and complement components in bind- 
Table 3. Identification of human plasma proteins attached to the cell surface of $C$. parapsilosis and $C$. tropicalis cells grown in YPD broth or RPMI 1640 medium supplemented with $10 \%$ of human plasma and indication of fungal proteins, whose exposure at the cell surface under these conditions was at least three-fold higher than in a medium without plasma (marked with $\uparrow$ ).

After cell surface shaving, peptides were analyzed using the Dionex Ultimate 3000 UHPLC system coupled to an HCTUltra ETDII mass spectrometer. The obtained lists of peaks were searched against the NCBI protein database and SwissProt protein database using an inhouse Mascot server.

\begin{tabular}{|c|c|c|}
\hline & Surface-bound human proteins & Surface-exposed fungal proteins \\
\hline C. parapsilosis & $\begin{array}{l}\text { alpha-1-antitrypsin } \\
\text { alpha-2-HS-glycoprotein } \\
\text { apolipoprotein A-1 } \\
\text { apolipoprotein A-II } \\
\text { apolipoprotein A-IV } \\
\text { apolipoprotein B-100 } \\
\text { apolipoprotein E } \\
\text { clusterin } \\
\text { complement C3 } \\
\text { complement C4-A } \\
\text { complement C5 } \\
\text { complement component C9 } \\
\text { complement factor B } \\
\text { fibrinogen chain alpha } \\
\text { gelsolin } \\
\text { fibrinogen chain beta } \\
\text { heparin cofactor } 2 \\
\text { fibrinogen chain gamma } \\
\text { paraoxonase/arylesterase } 1 \\
\text { vitronectin } \\
\text { serum albumin } \\
\text { serum amyloid A-4 protein }\end{array}$ & $\begin{array}{l}\text { hypothetical protein CPAR2_407410, similar to C. albicans cell } \\
\text { surface mannoprotein (Mp65) } \\
\text { hypothetical protein CPAR2_502140, similar to C. albicans } \\
\text { GPI-linked chitinase (Cht2) } \\
\text { hypothetical protein CPAR2_806490, similar to C. albicans protein } \\
\text { with internal repeats (Pir1) } \uparrow \\
\text { hypothetical protein CPAR2_400860, similar to C. albicans } \\
\text { GPI-anchored cell wall transglycosylase (Crh11) } \\
\text { hypothetical protein CPAR2_108560, similar to C. albicans } \\
\text { GPI-anchored cell wall protein (Ecm33) } \uparrow \\
\text { CFEM5, putative membrane protein with unknown function } \uparrow\end{array}$ \\
\hline C. tropicalis & $\begin{array}{l}\text { alpha-1-antitrypsin } \\
\text { angiotensinogen } \\
\text { apolipoprotein A-1 } \\
\text { apolipoprotein A-IV } \\
\text { apolipoprotein B-100 } \\
\text { apolipoprotein C-III } \\
\text { apolipoprotein E } \\
\text { clusterin } \\
\text { complement C3 } \\
\text { complement C4-A } \\
\text { complement C5 } \\
\text { complement component C9 } \\
\text { fibrinogen chain alpha } \\
\text { gelsolin } \\
\text { fibrinogen chain beta } \\
\text { hemoglobin subunit beta } \\
\text { fibrinogen chain gamma } \\
\text { heparin cofactor 2 } \\
\text { paraoxonase/arylesterase } 1 \\
\text { vitronectin } \\
\text { serum albumin }\end{array}$ & $\begin{array}{l}\text { predicted protein similar to C. albicans cell wall protein with } \\
\text { similarity to Hwp1 (Rbt1) } \uparrow \\
\text { conserved hypothetical protein similar to C. albicans cell-wall } \\
\text { agglutinin-like sequence protein (Als1) } \uparrow \\
\text { glyceraldehyde-3-phosphate dehydrogenase (Tdh3) } \uparrow\end{array}$ \\
\hline
\end{tabular}

ing to the cell surface of C. parapsilosis and C. tropicalis as compared to other plasma proteins. In addition, the alpha-1-antitrypsin (a protease inhibitor from serpin family), three chains of fibrinogen, and vitronectin - a glycoprotein found not only in plasma, but also in extracellular matrix - as well as the most abundant plasma protein, namely albumin, were also found at the cell surface of both investigated species. A noticeable difference between these two species concerned alpha2-HS-glycoprotein (cystatin type 3) and serum amyloid protein identification in case of $C$. parapsilosis cells and hemoglobin beta subunit- and angiotensinogen binding noticed in the case of $C$. tropicalis cells.

\section{DISCUSSION}

The candidal cell wall is a dynamic and complicated structure, in the large part built of polysaccharides but the proteins are thought to be the main players in the initiation of the contact with host proteins and cells, and in further development of infection (Chaffin, 2008). Therefore, the identification of surface-exposed proteins of two emerging fungal pathogens - C. parapsilosis and
C. tropicalis - might provide new, important insights into molecular determinants of their pathogenesis. Recently, the cell wall proteomes of several pathogenic fungi have been extensively studied using a broad range of different fractionating methods combined with mass spectrometry (Karkowska-Kuleta \& Kozik, 2015). Nevertheless, the complete proteomes of $C$. parapsilosis and C. tropicalis are not yet fully recognized; however, some first reports of the presence of enolase, elongation factor 1-beta, heat shock protein Ssb1, fructose-bisphosphate aldolase and glyceraldehyde-3-phosphate dehydrogenase at the cell surface of $C$. parapsilosis yeast-like cells under conditions of oxidative stress have recently been published (Ramírez-Quijas et al., 2015).

In this work, an uncomplicated and fast method based on tryptic digestion of proteins exposed at the cell surface of live cells was used, enabling us to characterize the surfaceome of two investigated Candida species. In comparison to the most recent studies concerning the cell surface shaving of $C$. albicans yeast and hyphal cells (Gil-Bona et al., 2015b), our analyses showed both similarities and differences between this most widespread opportunistic pathogen and the two investigated nonalbicans Candida species. Among the twenty most abun- 
dant surface-exposed proteins indicated by Gil-Bona et al. (2015b) for C. albicans yeast forms, we found orthologs of Tdh3 and Eno1 in both non-albicans Candida species and, additionally, of Mp65 and Adh1 in C. parapsilosis, and of Pgk1 and Wh11 in C. tropicalis. However, in comparison to the most abundant proteins identified at the cell surface of $C$. albicans filamentous forms, in the present study only Tdh3 ortholog was found in the highest abundance among $C$. tropicalis proteins. Nevertheless, many other proteins identified by us at the cell surface of $C$. parapsilosis and $C$. tropicalis have their orthologs at the surface of $C$. albicans yeast or hyphae listed by GilBona et al. (2015b) as proteins present at the cell wall with a lower abundance.

Because Tdh3, Eno1, Pgk1 and Adh1 are enzymes derived from cytoplasm and involved in glycolysis, gluconeogenesis and fermentation, their presence at the cell surface, although usually considered as atypical, is often described in literature on C. albicans (Gil-Navarro et al., 1997; Urban et al., 2003; López-Villar et al., 2006; Karkowska-Kuleta \& Kozik, 2014). These proteins are also reported as immunogenic during infections in humans (Pitarch et al., 2001; Fernández-Arenas et al., 2004; Pitarch et al., 2004) and as molecules involved in binding of human host proteins, i.e., plasminogen, kininogen, integrins and extracellular matrix proteins (Gozalbo et al., 1998; Klotz et al., 2001; Jong et al., 2003; Crowe et al., 2003; Karkowska-Kuleta et al., 2011). Admittedly, a question how such proteins are exported from cytoplasm is still relevant. Different mechanisms have been proposed to clarify this issue, including secretion of extracellular vesicles, membrane flipping, ineligible entry to secretory vesicles or exosome release (Nombela et al., 2006; Nickel \& Rabouille, 2009; Gil-Bona et al., 2015a). On the other hand, there is still a concern, that such cytoplasmic proteins might originate from damaged cells; however, a strict control of cell viability during experiments performed in this study allowed to largely avoid such artifacts.

Apart from those four abovementioned proteins, some other cytoplasmic proteins have been identified in this study at C. parapsilosis or C. tropicalis cell surface, including heat shock proteins, elongation factors and subunits of ATP synthase, especially in nitrogen-limited medium YAPD. The increased presence of this group of proteins at the cell surface might lead to a conclusion, that these particular growth conditions not only induce filamentation, but might also stimulate the fungal cell's response to environmental stress and trigger the adaptive changes within the cell wall (Lee et al., 2014; Rane et al., 2014; Ramírez-Quijas et al., 2015).

Furthermore, a well represented group of proteins involved in the cell wall building and maintenance was observed in this study both for C. tropicalis and C. parapsilosis cells. These proteins are mainly covalently bound to the cell wall, in contrast to those discussed above. Therefore, they are often called typical or classical cell wall proteins. There are at least three main types of linkages between proteins and a polysaccharide scaffold, including GPI-anchoring, alkali-sensitive linkages (ASL) and disulfide bridges; however, there is a large body of evidence that different mixed types of bonds occur within such the complicated structure of the cell wall (de Groot et al., 2004; Pitarch et al., 2008; Klis et al., 2009; Boisramé et al., 2011). Several of these typical proteins can be involved in adhesion to host proteins, thus contributing to fungal virulence and invasion of a human organism. One example is glucanase Mp65, a cell surface mannoprotein bound to $C$. albicans cell wall via ASL and disulfide bridges (Caminero et al., 2014) that also acts as an antigen and an adhesin strongly related to C. albicans virulence (Sandini et al., 2011). We found an orthologous protein similar to Mp65 both at the surface of C. parapsilosis yeast-like cells and pseudohyphae — where it was the most abundant protein — as well as at the surface of both morphological forms of C. tropicalis. As Mp65 is involved in the adhesion to plastics (Sandini et al., 2007), this observation might partially elucidate the high ability of C. parapsilosis to adhere to and form biofilms at the artificial surfaces, including a variety of medical devices (Trofa et al., 2008). Other important proteins involved in the cell wall maintenance were identified at the cell surface of non-albicans Candida species with the use of trypsin shaving. For C. parapsilosis, at least the following orthologous proteins should be mentioned: Cht2, Ecm33, Phr2 and Crh11 anchored to cell wall via GPI remnant (de Groot et al., 2004; Castillo et al., 2008), Eng1 and Bgl2 attached to the cell wall via ASL and/or disulfide bonds (Caminero et al., 2014) and Pir1, a structural protein attached to cell wall $\beta-1,3$-glucan through ASL (de Groot et al., 2004). An ortholog of the latter was also identified in C. tropicalis cell wall.

Among some interesting putative GPI-anchored proteins, in this study we identified a protein similar to Plb5 at the surface of $C$. parapsilosis pseudohyphae. At the cell surface of $C$. tropicalis pseudohyphae, apart from an ortholog of Rbt1 - a GPI-linked protein with a similarity to Hwp1, required for fungal virulence (Braun et al., 2000) - we also found two proteins from distinct large families gathering important adhesins, namely agglutininlike sequence (Als) protein family and Iff/Hyr protein family. This observation suggests that like in the case of C. albicans, C. tropicalis filamentous forms possess strongly adhesive properties that help this pathogen to invade the host organism. It is well known that formation of filamentous forms is the essential step for full fungal pathogenicity (Diez-Orejas et al., 1999; Thompson et al., 2011).

The important role in C. tropicalis of a protein similar to $\mathrm{Rbt} 1$, a protein from Als protein family, and additionally Tdh3 during the invasion might be confirmed by the observed increase of the quantity of these proteins at the cell surface after growth in the medium containing human plasma, which mimics - to some extent - the contact with host proteins during bloodstream infection. In case of $C$. parapsilosis, an analogous effect was found for proteins similar to Pir1, Ecm33 and CFEM5. On the other hand, the investigation of surfaceome under these conditions preliminarily revealed a set of human proteins that can adhere to the fungal cell surface. Among them, as expected, the most abundant human plasma protein — albumin — was found, but several apolipoproteins, complement components and other proteins were also identified, not only ones most abundantly present, but also those less frequently represented in the plasma (Anderson \& Anderson, 2002). Because a key role of the complement cascade in innate immunity is to recognize and eliminate pathogenic microorganisms from bloodstream after their opsonization or perforation of their cellular membranes via membrane-attacking complex engaging complement component C9 (Peitsch \& Tschopp, 1991), its function for host defense during disseminated candidiasis is essential (Boxx et al., 2010). Hence, the identification at the $C$. parapsilosis and $C$. tropicalis cell surface of several complement components - C3, C4-A, C5, C9 - after the contact of fungal cells with human plasma might be related to triggering the complement pathways activation, following the binding of its components to the fungal surface. However, it is well known, 
at least in the case of C. albicans, that some surface-exposed proteins, such as Pra1, Gpm1 and Gpd2, might be involved in the binding of a few complement factors and regulators - C4BP, factor $\mathrm{H}$ and FHL1 - thereby participating in gaining control over this system by the fungus in order to inhibit complement activation and to facilitate immune evasion (Poltermann et al., 2007; Luo et al., 2011; Luo et al., 2013). There is also some evidence, that representatives of the second, most abundant group of proteins shown herein as bound to $C$. parapsilosis and C. tropicalis cell surface - namely apolipoproteins - might play an important role in the host resistance against fungal infections (Vonk et al., 2004). What is more, the plasma amyloid protein, found here as adhered to the cell surface of $C$. parapsilosis, is also a chemoattractant for polymorphonuclear cells, increasing their antifungal action (Badolato et al., 2000).

Apart from these strongly represented groups of human proteins - the complement components and apolipoproteins - fibrinogen and vitronectin were also identified as attached to the C. parapsilosis and C. tropicalis cell surface. As the latter is the important, adhesive protein present not only in plasma but also in the extracellular matrix, its binding may promote fungal adhesion to host tissues during the first step of infection and further dissemination of fungal cells within the organism via a circulatory system (Lopez et al., 2014). It should be noted that hijacking the important host system such as the coagulation cascade by pathogens greatly facilitates their pathogenicity and it is a well known process occurring during bacterial infections (Rivera et al., 2007).

One of the surface-bound human proteins identified in the case of $C$. tropicalis was hemoglobin, being not only the necessary and important source of iron for microorganism, but also the stimulator of increased adhesin exposure (i.e., of Hwp1) at the fungal cell surface and development of the hyphal forms as it has been previously described for C. albicans (Yan et al., 1998; Pendrak \& Roberts, 2007). Quite similar results, corroborating with data obtained for C. parapsilosis and C. tropicalis and concerning the host plasma proteins' binding to fungal cell surface, were described for another important fungal pathogen of humans, Paracoccidioides brasiliensis. In the case of this species, complement factor C3, albumin, vitronectin, fibrinogen, alpha-1-antitrypsin, angiotensinogen, apolipoproteins B-100 and A-1, paraoxonase/arylesterase 1 and alpha-2-HS-glycoprotein were identified (Longo et al., 2013). Due to such reports it now becomes possible to recognize more thoroughly the various aspects of interactions between fungal pathogen and a human host.

To our knowledge, this work is the first study describing the surfaceome - the proteome of cell surface of two non-albicans Candida species, i.e., C. parapsilosis and $C$. tropicalis, albeit for the former species there is now some information available about a few proteins exposed at the cell surface of the yeast-like cells during the oxidative stress (Ramírez-Quijas et al., 2015). Revealing the Candida spp. cell wall protein composition with the use of proteomic methods and mass spectrometry is a very important contribution to the exploration of potentially new virulence attributes of these fungi. However, addressing the physiological and functional questions related to the known proteome is also of a great importance. Recently, important attempts to indicate the immunogenic proteins of $C$. parapsilosis and C. tropicalis were made, with a finding of twelve proteins for each species as inducing the antibody response (Lee et al., 2014a; Lee et al., 2014b). In the current study we confirmed the presence of some of them at the cell surface of C. parapsilosis cells, i.e., proteins similar to Adh1, Atp1, Eno1, Tdh3 and Pdc11, and C. tropicalis cells, i.e., proteins similar to Atp2, Eno1, Tdh3 and Tpi1.

As the particular species of Candida genus are considered to differ from each another in molecular mechanisms of pathogenicity, drug resistance, epidemiology, risk factors among various groups of infected patients and the level of mortality (Krcmery \& Barnes, 2002), these differences might be reflected in the set of proteins exposed at their cell surface. In the case of $C$. tropicalis, the frequent presence of alkaline and acid phosphatases was particularly interesting and correlated with previous findings (Sangar et al., 1975), and this feature distinguishes $C$. tropicalis from other Candida species diagnostically.

To summarize, the obtained results might markedly contribute to a better understanding of the complicated phenomenon - the host-pathogen interaction during candidal infections - and significantly expand the scope of designing new antifungal drugs, vaccines and diagnostic methods for other species of the Candida genus.

\section{Acknowledgements}

This work was supported in part by the National Science Centre of Poland (grant no. 2012/07/B/ NZ1/02867 awarded to A.K.). The Faculty of Biochemistry, Biophysics and Biotechnology of the Jagiellonian University in Krakow is a beneficiary of structural funds from the European Union (grant no. POIG.02.01.0012-064/08, "Molecular biotechnology for health") and a partner of the Leading National Research Center (KNOW) supported by the Ministry of Science and Higher Education, Poland.

The authors declare that there are no conflicts of interest.

\section{REFERENCES}

Anderson NL, Anderson NG (2002) The human plasma proteome: history, character, and diagnostic prospects. Mol Cell Proteomics 1: 845-867.

Arendrup MC (2013) Candida and candidaemia. Susceptibility and epidemiology. Dan Med J 60: B4698.

Azie N, Neofytos D, Pfaller M, Meier-Kriesche HU, Quan SP, Horn D (2012) The PATH (Prospective Antifungal Therapy) Alliance® registry and invasive fungal infections: update 2012. Diagn Microbiol Infect Dis 73: 293-300. http://dx.doi: 10.1016/j.diagmicrobio.2012.06.012

Badolato R, Wang JM, Stornello SL, Ponzi AN, Duse M, Musso T (2000) Plasma amyloid A is an activator of PMN antimicrobial functions: induction of degranulation, phagocytosis, and enhancement of anti-Candida activity. J Leukoc Biol 67: 381-386.

Boisramé A, Cornu A, Da Costa G, Richard ML (2011) Unexpected role for a serine/threonine-rich domain in the Candida albicans Iff protein family. Eukaryot Cell 10: 1317-1330. http://dx.doi: 10.1128/ EC.05044-11.

Boxx GM, Kozel TR, Nishiya CT, Zhang MX (2010) Influence of mannan and glucan on complement activation and $\mathrm{C} 3$ binding by Candida albicans. Infect Immun 78: 1250-1259. http://dx.doi: 10.1128/ IAI.00744-09.

Braun BR, Head WS, Wang MX, Johnson AD (2000) Identification and characterization of TUP1-regulated genes in Candida albicans. Genetics 156: 31-44.

Butler G, Rasmussen MD, Lin MF, Santos MA, Sakthikumar S, Munro CA et al. (2009) Evolution of pathogenicity and sexual reproduction in eight Candida genomes. Nature 459: 657-662. http://dx.doi: 10.1038 / nature08064.

Caminero A, Calvo E, Valentín E, Ruiz-Herrera J, López JA, Sentandreu R (2014) Identification of Candida albicans wall mannoproteins covalently linked by disulphide and/or alkali-sensitive bridges. Yeast 31: 137-144. http://dx.doi: 10.1002/yea.3003.

Castillo L, Calvo E, Martínez AI, Ruiz-Herrera J, Valentín E, Lopez JA, Sentandreu R (2008) A study of the Candida albicans cell wall proteome. Proteomics 8: 3871-3881. http://dx.doi: 10.1002/ pmic. 200800110 . 
Chaffin WL (2008) Candida albicans cell wall proteins. Microbiol Mol Biol Rev 72: 495-544. http://dx.doi: 10.1128/MMBR.00032-07.

Crowe JD, Sievwright IK, Auld GC, Moore NR, Gow NA, Booth NA (2003) Candida albicans binds human plasminogen: identification of eight plasminogen-binding proteins. Mol Microbiol 47: 1637-1651.

de Groot PW, de Boer AD, Cunningham J, Dekker HL, de Jong L, Hellingwerf KJ, de Koster C, Klis FM (2004) Proteomic analysis of Candida albicans cell walls reveals covalently bound carbohydrateactive enzymes and adhesins. Eukaryot Cell 3: 955-965.

de Groot PW, Kraneveld EA, Yin QY, Dekker HL, Gross U, Crielaard W, de Koster CG, Bader O, Klis FM, Weig M (2008) The cell wall of the human pathogen Candida glabrata: differential incorporation of novel adhesin-like wall proteins. Eukaryot Cell 7: 1951-1964. http://dx.doi: 10.1128/EC.00284-08.

Demuyser L, Jabra-Rizk MA, Van Dijck P (2014) Microbial cell surface proteins and secreted metabolites involved in multispecies biofilms. Pathog Dis 70: 219-230. http://dx.doi: 10.1111/2049-632X.12123.

Desvaux M, Dumas E, Chafsey I, Hébraud M (2006) Protein cell surface display in Gram-positive bacteria: from single protein to macromolecular protein structure. FEMS Microbiol 256: 1-15.

Diez-Orejas R, Molero G, Ríos-Serrano I, Vázquez A, Gil C, Nombela C, Sánchez-Pérez M (1999) Low virulence of a morphological Candida albicans mutant. FEMS Microbiol Lett 176: 311-319.

Eigenheer RA, Jin Lee Y, Blumwald E, Phinney BS, Gelli A (2007) Extracellular glycosylphosphatidylinositol-anchored mannoproteins and proteases of Cryptococcus neoformans. FEMS Yeast Res 7: 499-510.

Fernández-Arenas E, Molero G, Nombela C, Diez-Orejas R, Gil C (2004) Low virulent strains of Candida albicans: unravelling the antigens for a future vaccine. Proteomics 4: 3007-3020.

Free SJ (2013) Fungal cell wall organization and biosynthesis. Adv Genet 81: 33-82. http://dx.doi: 10.1016/B978-0-12-407677-8.00002-6

Gil-Bona A, Llama-Palacios A, Parra CM, Vivanco F, Nombela C, Monteoliva L, Gil C (2015a) Proteomics unravels extracellular vesicles as carriers of classical cytoplasmic proteins in Candida albicans. J Proteome Res 14: 142-153. http://dx.doi: 10.1021/pr5007944.

Gil-Bona A, Parra-Giraldo CM, Hernáez ML, Reales-Calderon JA, Solis NV, Filler SG, Monteoliva L, Gil C (2015b) Candida albicans cell shaving uncovers new proteins involved in cell wall integrity, yeast to hypha transition, stress response and host-pathogen interaction. J Proteomics pii:S1874-3919(15)30043-9. http://dx.doi: 10.1016/j. jprot.2015.06.006.

Gil-Navarro I, Gil ML, Casanova M, O’Connor JE, Martínez JP, Gozalbo D (1997) The glycolytic enzyme glyceraldehyde-3-phosphate dehydrogenase of Candida albicans is a surface antigen. J Bacteriol 179: 4992-4999.

Gozalbo D, Gil-Navarro I, Azorín I, Renau-Piqueras J, Martínez JP, Gil ML (1998) The cell wall-associated glyceraldehyde-3-phosphate dehydrogenase of Candida albicans is also a fibronectin and laminin binding protein. Infect Immun 66: 2052-2059.

Hecker M, Becher D, Fuchs S, Engelmann S (2010) A proteomic view of cell physiology and virulence of Staphylococcus aureus. Int J Med Microbiol 300: 76-87. http://dx.doi: 10.1016/j.ijmm.2009.10.006.

Hernáez ML, Ximénez-Embún P, Martínez-Gomariz M, GutiérrezBlázquez MD, Nombela C, Gil C (2010) Identification of Candida albicans exposed surface proteins in vivo by a rapid proteomic approach. J Proteomics 73: 1404-1409. http://dx.doi: 10.1016/j. jprot.2015.06.006.

Hoyer LL, S. Scherer S, A. R. Shatzman AR, Livi GP (1995) Candida albicans ALS1: domains related to a Saccharomyces cerevisiae sexual agglutinin separated by a repeating motif. Mol Microbiol 15: 39-54.

Huang SH, Triche T, Jong AY (2002) Infectomics: genomics and proteomics of microbial infections. Funct Integr Genomics 1:331-344.

Inglis DO, Arnaud MB, Binkley J, Shah P, Skrzypek MS, Wymore F, Binkley G, Miyasato SR, Simison M, Sherlock G (2012) The Candida genome database incorporates multiple Candida species: multispecies search and analysis tools with curated gene and protein information for Candida albicans and Candida glabrata. Nucleic Acids Res 40 (Database issue): D667-D674. http://dx.doi: 10.1093/nar/gkr945.

Insenser MR, Hernáez ML, Nombela C, Molina M, Molero G, Gil C (2010) Gel and gel-free proteomics to identify Saccharomyces cerevisiae cell surface proteins. J Proteomics 73: 1183-1195. http://dx.doi: 10.1016/j.jprot.2010.02.005.

Jong AY, Chen SH, Stins MF, Kim KS, Tuan TL, Huang SH (2003) Binding of Candida albicans enolase to plasmin(ogen) results in enhanced invasion of human brain microvascular endothelial cells. J Med Microbiol 52: 615-622.

Karkowska-Kuleta J, Kedracka-Krok S, Rapala-Kozik M, Kamysz W, Bielinska S, Karafova A, Kozik A (2011) Molecular determinants of the interaction between human high molecular weight kininogen and Candida albicans cell wall: Identification of kininogen-binding proteins on fungal cell wall and mapping the cell wall-binding regions on kininogen molecule. Peptides 32: 2488-2496. http://dx.doi: 10.1016/j.peptides.2011.10.021

Karkowska-Kuleta J, Kozik A (2014) Moonlighting proteins as virulence factors of pathogenic fungi, parasitic protozoa and multicellu- lar parasites. Mol Oral Microbiol 29: 270-283. http://dx.doi: 10.1111/ omi.12078.

Karkowska-Kuleta J, Kozik A (2015) Cell wall proteome of pathogenic fungi. Acta Biochim Pol 62: 339-351. http://dx.doi: 10.18388/ abp.2015_1032.

Klis FM, Sosinska GJ, de Groot PW, Brul S (2009) Covalently linked cell wall proteins of Candida albicans and their role in fitness and virulence. FEMS Yeast Res 9: 1013-1028. http://dx.doi: 10.1111/j.1567-1364.2009.00541.x.

Klotz SA, Pendrak ML, Hein RC (2001) Antibodies to alpha5beta1 and alpha(v)beta3 integrins react with Candida albicans alcohol dehydrogenase. Microbiology 147: 3159-3164.

Krcmery V, Barnes AJ (2002) Non-albicans Candida spp. causing fungaemia: pathogenicity and antifungal resistance. J Hosp Infect 50: 243-260.

Lee PY, Gam LH, Yong VC, Rosli R, Ng KP, Chong PP (2014a) Identification of immunogenic proteins of Candida parapsilosis by serological proteome analysis. J Appl Microbiol 116: 999-1009. http:// dx.doi: $10.1111 /$ jam.12408.

Lee PY, Gam LH, Yong VC, Rosli R, Ng KP, Chong PP (2014b) Immunoproteomic analysis of antibody response to cell wall-associated proteins of Candida tropicalis. I Appl Microbiol 117: 854-865. http:// dx.doi: 10.1111/jam.12562.

Lee SH, Chung SC, Shin J, Oh KB (2014) GST2 is required for nitrogen starvation-induced filamentous growth in Candida albicans. J Microbiol Biotechnol 24: 1207-1215.

Longo LV, Nakayasu ES, Matsuo AL, Peres da Silva R, Sobreira TJ, Vallejo MC, Ganiko L, Almeida IC, Puccia R (2013) Identification of human plasma proteins associated with the cell wall of the pathogenic fungus Paracoccidioides brasiliensis. FEMS Microbiol Lett 341: 87-95. http://dx.doi: 10.1111/1574-6968.12097.

Lopez CM, Wallich R, Riesbeck K, Skerka C, Zipfel PF (2014) Candida albicans uses the surface protein Gpm1 to attach to human endothelial cells and to keratinocytes via the adhesive protein vitronectin. PLoS One 9: e90796. http://dx.doi: 10.1371/journal.pone.0090796.

López-Villar E, Monteoliva L, Larsen MR, Sachon E, Shabaz M, Pardo M, Pla J, Gil C, Roepstorff P, Nombela C (2006) Genetic and proteomic evidences support the localization of yeast enolase in the cell surface. Proteomics 6: S107-S118.

Luo S, Blom AM, Rupp S, Hipler UC, Hube B, Skerka C, Zipfel PF (2011) The pH-regulated antigen 1 of Candida albicans binds the human complement inhibitor C4b-binding protein and mediates fungal complement evasion. J Biol Chem 286: 8021-8029. http://dx.doi: 10.1074/jbc.M110.130138.

Luo S, Hoffmann R, Skerka C, Zipfel PF (2013) Glycerol-3-phosphate dehydrogenase 2 is a novel factor $\mathrm{H}_{-}$, factor $\mathrm{H}$-like protein $1-$, and plasminogen-binding surface protein of Candida albicans. I Infect Dis 207: 594-603. http://dx.doi: 10.1093/infdis/jis718.

Modrzewska B, Kurnatowski P (2015) Adherence of Candida sp. to host tissues and cells as one of its pathogenicity features. Ann Parasitol 61: 3-9.

Nickel W, Rabouille C (2009) Mechanisms of regulated unconventional protein secretion. Nat Rev Mol Cell Biol 10: 148-155. http://dx.doi: $10.1038 / \mathrm{nrm} 2617$.

Nombela C, Gil C, Chaffin WL (2006) Non-conventional protein secretion in yeast. Trends Microbiol 14: 15-21.

Olaya-Abril A, Jiménez-Munguía I, Gómez-Gascón L, Rodríguez-Ortega MJ (2014) Surfomics: shaving live organisms for a fast proteomic identification of surface proteins. J Proteomics 97: 164-176. http:// dx.doi: 10.1016/j.jprot.2013.03.035.

Peitsch MC, Tschopp J (1991) Assembly of macromolecular pores by immune defense systems. Curr Opin Cell Biol 3: 710-716.

Pendrak ML, Roberts DD (2007) Hemoglobin is an effective inducer of hyphal differentiation in Candida albicans. Med Mycol 45: 61-71.

Pitarch A, Abian J, Carrascal M, Sánchez M, Nombela C, Gil C (2004) Proteomics-based identification of novel Candida albicans antigens for diagnosis of systemic candidiasis in patients with underlying hematological malignancies. Proteomics 4: 3084-3106.

Pitarch A, Díez-Orejas R, Molero G, Pardo M, Sánchez M, Gil C, Nombela C (2001) Analysis of the serologic response to systemic Candida albicans infection in a murine model. Proteomics 1: 550-559.

Pitarch A, Nombela C, Gil C (2008) Cell wall fractionation for yeast and fungal proteomics. Methods Mol Biol 425: 217-239. http:// dx.doi: 10.1007/978-1-60327-210-0_19.

Pitarch A, Sánchez M, Nombela C, Gil C (2002) Sequential fractionation and two-dimensional gel analysis unravels the complexity of the dimorphic fungus Candida albicans cell wall proteome. Mol Cell Proteomics 1: 967-982.

Poltermann S, Kunert A, von der Heide M, Eck R, Hartmann A, Zipfel PF (2007) Gpm1p is a factor H-, FHL-1-, and plasminogenbinding surface protein of Candida albicans. J Biol Chem 282: $37537-$ 37544.

Ramírez-Quijas MD, López-Romero E, Cuéllar-Cruz M (2015) Proteomic analysis of cell wall in four pathogenic species of Candida exposed to oxidative stress. Microb Pathog 87: 1-12. http://dx. doi: 10.1016/j.micpath.2015.07.011. 
Rane HS, Bernardo SM, Hayek SR, Binder JL, Parra KJ, Lee SA (2014) The contribution of Candida albicans vacuolar ATPase subunit $V_{1} B$, encoded by VMA2, to stress response, autophagy, and virulence is independent of environmental pH. Eukaryot Cell 13: 1207-1221. http://dx.doi: 10.1128/EC.00135-14.

Rapala-Kozik M, Karkowska-Kuleta J, Ryzanowska A, Golda A, Barbasz A, Faussner A, Kozik A (2010) Degradation of human kininogens with the release of kinin peptides by extracellular proteinases of Candida spp. Biol Chem 391: 823-830. http://dx.doi: 10.1515/ BC.2010.083.

Rivera J, Vannakambadi G, Höök M, Speziale P (2007) Fibrinogenbinding proteins of Gram-positive bacteria. Thromb Haemost 98: $503-511$.

Sandini S, La Valle R, De Bernardis F, Macrì C, Cassone A (2007) The $65 \mathrm{kDa}$ mannoprotein gene of Candida albicans encodes a putative beta-glucanase adhesin required for hyphal morphogenesis and experimental pathogenicity. Cell Microbiol 9: 1223-1238.

Sandini S, Stringaro A, Arancia S, Colone M, Mondello F, Murtas S, Girolamo A, Mastrangelo N, De Bernardis F (2011) The MP65 gene is required for cell wall integrity, adherence to epithelial cells and biofilm formation in Candida albicans. BMC Microbiol 11: 106. http://dx.doi: 10.1186/1471-2180-11-106.

Sangar VK, Cortes JM, Self LW (1975) Acid phosphatase production as an aid in rapid characterization of Candida species. Am J Med Technol 41: 327-332.

Severin A, Nickbarg E, Wooters J, Quazi SA, Matsuka YV, Murphy E, Moutsatsos IK, Zagursky RJ, Olmsted SB (2007) Proteomic analysis and identification of Streptococcus pyogenes surface-associated proteins. J Bacteriol 189: 1514-1522.

Silhavy TJ, Kahne D, Walker S (2010) The bacterial cell envelope. Cold Spring Harb Perspect Biol 2: a000414. http://dx.doi: 10.1101/cshperspect.a000414.

Solis N, Cordwell SJ (2011) Current methodologies for proteomics of bacterial surface-exposed and cell envelope proteins. Proteomics 11: 3169-3189. http://dx.doi: 10.1002/pmic.201000808.

Solis N, Larsen MR, Cordwell SJ (2010) Improved accuracy of cell surface shaving proteomics in Staphylococcus aureus using a false- positive control. Proteomics 10: 2037-2049. http://dx.doi: 10.1002/ pmic. 200900564

Sturtevant J (2000) Applications of differential-display reverse transcription-PCR to molecular pathogenesis and medical mycology. Clin Microbiol Rev 13: 408-427.

Thompson DS, Carlisle PL, Kadosh D (2011) Coevolution of morphology and virulence in Candida species. Eukaryot Cell 10: 11731182. http://dx.doi: 10.1128/EC.05085-11.

Trofa D, Gácser A, Nosanchuk JD (2008) Candida parapsilosis, an emerging fungal pathogen. Clin Microbiol Rev 21: 606-625. http:// dx.doi: 10.1128/CMR.00013-08.

Urban C, Sohn K, Lottspeich F, Brunner H, Rupp S (2003) Identification of cell surface determinants in Candida albicans reveals Tsa1p, a protein differentially localized in the cell. FEBS Lett 544: 228-235.

Vialás V, Perumal P, Gutierrez D, Ximénez-Embún P, Nombela C, Gil C, Chaffin WL (2012) Cell surface shaving of Candida albicans biofilms, hyphae, and yeast form cells. Proteomics 12: 2331-2339. http:// dx.doi: 10.1002/pmic.201100588

Vonk AG, De Bont N, Netea MG, Demacker PN, van der Meer JW, Stalenhoef AF, Kullberg BJ (2004) Apolipoprotein-E-deficient mice exhibit an increased susceptibility to disseminated candidiasis. Med Mycol 42: 341-348.

Walters MS, Mobley HL (2009) Identification of uropathogenic Escherichia coli surface proteins by shotgun proteomics. J Microbiol Methods 78: 131-135. http://dx.doi: 10.1016/j.mimet.2009.04.013.

Wang H, Liu N, Yin M, Han H, Yue J, Zhang F, Shan T, Guo H, Wu D (2014) The epidemiology, antifungal use and risk factors of death in elderly patients with candidemia: a multicentre retrospective study. BMC Infect Dis 14: 609. http://dx.doi: 10.1186/s12879014-0609-x.

Yan S, Rodrigues RG, Cahn-Hidalgo D, Walsh TJ, Roberts DD (1998) Hemoglobin induces binding of several extracellular matrix proteins to Candida albicans. Identification of a common receptor for fibronectin, fibrinogen, and laminin. J Biol Chem 273: 5638-5644.

Zybailov BL, Florens L, Washburn MP (2007) Quantitative shotgun proteomics using a protease with broad specificity and normalized spectral abundance factors. Mol Biosyst 3: 354-360. 